\title{
Destructive and Nondestructive Procedures to Obtain Chicken Carcass Samples for Escherichia coli and Salmonella spp. Detection
}

\author{
Marcus Vinícius Coutinho Cossi, Michelle Vieira de Almeida, Mariane Rezende Dias, \\ Paulo Sérgio de Arruda Pinto, and Luís Augusto Nero
}

\begin{abstract}
Destructive and nondestructive sampling procedures were compared for Escherichia coli and Salmonella spp. detection in 60 fresh chicken carcasses, which were submitted to the following sampling procedures: rinsing, skin swabbing, tissue excision, and skin excision; the proximity or not to the cloacae region was also considered. The obtained results were compared to identify significant differences $(p<0.05)$. Forty eight chicken carcasses were positive for E. coli, and five were positive for Salmonella spp. For E. coli, nonsignificant differences were observed between rinsing and tissue excision, rinsing and skin excision, and skin excision and tissue excision $(p>0.05)$, thus indicating equivalencies between these techniques. Skin swabbing produced a statistically significant lower frequency of positive results $(p<0.05)$ than all other techniques for $E$. coli, thus indicating its inadequacy for detection of this microorganism. For Salmonella spp., no significant differences were observed between the sampling techniques $(p>0.05)$, possibly due to the low overall frequency of positive carcasses. No significant differences in the number of positive samples (E. coli or Salmonella spp.) were observed between samples collected near or far from the cloacae region $(p>0.05)$, regardless of the sampling technique. The obtained results demonstrate that the tested sampling techniques were equivalent for Salmonella spp. detection in chicken carcasses, as observed for E. coli with the exception of skin swabbing.
\end{abstract}

\section{Introduction}

$\mathbf{S}_{\mathrm{o} \text { r }}^{\mathrm{p}}$ POILAGE AND PATHOGENIC microorganism contamination of chicken carcasses and avian products are constant concerns for the food industry and public health agencies in several countries (Álvarez-Astorga et al., 2002). Salmonella spp. is the main foodborne pathogen associated with these products, and is recognized as responsible for several food poisoning outbreaks, due to the consumption of contaminated avian products (Rasschaert et al., 2008; Vandeplas et al., 2010). When present in birds' gastrointestinal systems, Salmonella spp. can easily contaminate carcasses during slaughter, usually by some processing failures, such as bowel rupture (Reiter et al., 2007; Rasschaert et al., 2008).

The presence of enteric microorganisms in foods is used as a possible indicative of Salmonella spp. contamination; and in addition, it suggests poor hygienic conditions during production and processing (Álvarez-Astorga et al., 2002; Ghafir et al., 2008). Escherichia coli is considered a good indicator of both poor hygiene in industrial slaughter and production, and the possible presence of foodborne pathogens (Ghafir et al., 2008). In addition, several E. coli strains are also pathogenic, justifying testing for this microorganism in foods, including avian products (Tsola et al., 2008).

Sampling procedures are fundamental to the reliability of tests for the presence of specific microbial groups of foodborne pathogens in food. Several sampling procedures are used for animal carcasses, and are typically classified as destructive or nondestructive (Snijders et al., 1984; Capita et al., 2004). Considering their specific advantages and disadvantages (Palumbo et al., 1999; Capita et al., 2004), the best sampling procedure can be chosen by specific food industries or regulatory agencies to obtain reliable data for microbial monitoring (Gill and Jones, 2000). The objective of the current study was to compare destructive and nondestructive chicken carcass sampling techniques for the detection of E. coli and Salmonella spp., and to evaluate their limitations and possible equivalencies.

\section{Materials and Methods}

Chicken carcasses

A total of 60 fresh chicken carcasses were obtained from commercial establishments in Viçosa city and the surrounding region, in the state of Minas Gerais, Brazil. Each carcass

Departamento de Veterinária, Universidade Federal de Viçosa, Viçosa, Brazil. 
was collected in its commercial package, and kept under refrigeration in isothermal containers until analysis.

\section{Sampling techniques and dilution}

Under aseptic conditions, each carcass was divided into two halves along the longitudinal section of its spine by using a sterile knife (Fig. 1). One half of the carcass was used to obtain a rinsing (nondestructive) sample, using a procedure modified from the USDA/FSIS (2008). The other half of the carcass was submitted to sampling by using two destructive (tissue excision and skin excision) and one nondestructive (skin swabbing) procedure, according to Gill et al. (2006). The breast and back regions of this half-carcass were divided into six areas of $25 \mathrm{~cm}^{2}$ $(5 \times 5 \mathrm{~cm})$ by using sterile templates for reference, to obtain samples according to cited procedures (see Fig. 1). For each procedure (with the exception of rinsing), two areas were randomly selected from the breast and back regions of the carcass and from areas near or far from the cloacae region.

For rinsing (nondestructive), the half carcass was placed in a sterile bag and weighed, and an equal amount (in $\mathrm{mL}$ ) of buffered $0.1 \%$ peptone water (Oxoid Ltd., Basingstoke, England) was added. Then, the contents of the bag were manually homogenized for $5 \mathrm{~min}$, and the final homogenate was collected in a sterile flask. The final sample concentration was defined as $1 \mathrm{~mL}=1 \mathrm{~g}$ of the carcass.

Skin swabbing (nondestructive) samples were obtained by swabbing selected areas of the carcass with moistened ( $5 \mathrm{~mL}$ of buffered $0.1 \%$ peptone water; Oxoid) sterile sponges. Sponges were collected in sterile bags with $45 \mathrm{~mL}$ of buffered $0.1 \%$ peptone water and automatically homogenized for $5 \mathrm{~min}$ (Stomacher ${ }^{\circledR} 400$ Circulator; Seward Ltd., Sussex, England). The final sample concentration was defined as $1 \mathrm{~mL}=1 \mathrm{~cm}^{2}$ of the carcass.

Tissue excision (destructive) samples were obtained by excision of skin and tissue fragments from selected areas of the carcass by using sterile scalpels and pincers. Tissue excision samples were collected in sterile bags until a weight of $25 \mathrm{~g}$ was obtained. Then, $225 \mathrm{~mL}$ of buffered $0.1 \%$ peptone water (Oxoid) was added, and the mixture was automatically homogenized for $5 \mathrm{~min}$ (Stomacher 400 Circulator). The final sample concentration was defined as $1 \mathrm{~mL}=0.1 \mathrm{~g}$ of the carcass (1:10).

Skin excision (destructive) samples were obtained by excision of skin from selected areas of the carcass by using sterile scalpels and pincers. Skin excision samples were collected in sterile bags containing $50 \mathrm{~mL}$ of buffered $0.1 \%$ peptone water (Oxoid) and automatically homogenized for $5 \mathrm{~min}$ (Stomacher 400 Circulator). The final sample concentration was defined as $1 \mathrm{~mL}=1 \mathrm{~cm}^{2}$ of the carcass.

All the obtained homogenates were then ten-fold diluted by using buffered $0.1 \%$ peptone water (Oxoid).

\section{E. coli detection}

For each chicken carcass and sampling technique, a 1:100 sample dilution was plated on Petrifilm ${ }^{\mathrm{TM}}$ Escherichia coli (3M Microbiology, St. Paul, MN) for E. coli detection, followed by incubation at $35^{\circ} \mathrm{C}$ for $48 \mathrm{~h}$. The presence of counts of 100 colony forming units per $\mathrm{g}$ or $\mathrm{cm}^{2}\left(\mathrm{cfu} / \mathrm{g}\right.$ or $\left.\mathrm{cfu} / \mathrm{cm}^{2}\right)$ or higher was considered a positive result for E. coli (a typical colony is blue in color, associated with gas formation). This concentration was considered a reference for the presence of E. coli, once it is used as a quality and safety parameter for foods in the United States and other countries (ÁlvarezAstorga et al., 2002; USDA, 2003).

\section{Salmonella spp. detection}

Samples from each sampling technique were submitted for Salmonella spp. detection according to a protocol modified from ISO 6579 (ISO, 2002). Aliquots containing $25 \mathrm{~g}$ (tissue excision samples) or $25 \mathrm{~mL}$ (rinsing, skin swabbing, and skin excision samples) of the final homogenates were added to $225 \mathrm{~mL}$ of buffered $1 \%$ peptone water (Oxoid), and incubated at $37^{\circ} \mathrm{C}$ for $18 \mathrm{~h}$ (pre-enrichment step). Then, $1 \mathrm{~mL}$ of the resulting culture was inoculated in $10 \mathrm{~mL}$ of selenite cysteine broth (Oxoid; incubated at $37^{\circ} \mathrm{C}$ for $24 \mathrm{~h}$ ). About $0.1 \mathrm{~mL}$ of this culture was then inoculated in $10 \mathrm{~mL}$ of Rappaport-Vassiliadis enrichment broth (Oxoid; incubated at $42.5^{\circ} \mathrm{C}$ for $24 \mathrm{~h}$ ) (selective enrichment step). After incubation, culture aliquots were streaked on brilliant green phenol red lactose sucrose
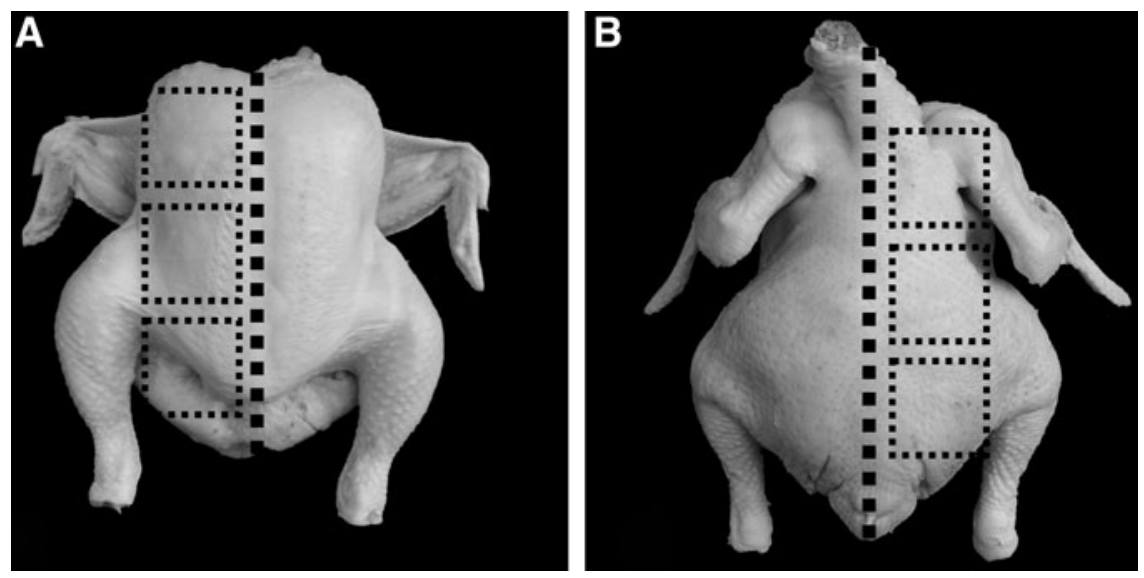

FIG. 1. Front (A) and dorsal (B) view of a typical chicken carcass, demonstrating division of the carcass into two halves (a dotted line marks the middle of the carcass). One half of the carcass was reserved for sampling by rinsing. Six areas (dotted line squares) were defined on the other half of the carcass to obtain samples by tissue excision, skin excision, and skin swabbing. 
Table 1. Overall Frequency of Positive Results FOR ESCHERICHIA COLI ( $\geq 100 \mathrm{CFU} / \mathrm{G}$ OR $\left.\mathrm{CM}^{2}\right)$ AND SALMONELLA SPP. OBTAINED By Distinct Sampling Procedures of Fresh Chicken Carcasses Collected from Retail Stores located at Viçosa, Minas Gerais, BraziL

\begin{tabular}{ll}
\hline $\begin{array}{l}\text { Sampling } \\
\text { procedure }\end{array}$ & Escherichia coli \\
\hline
\end{tabular}

\begin{tabular}{lll}
\hline Rinsing carcass & 40 & 2 \\
Tissue excision & 40 & 2 \\
Skin excision & 34 & 2 \\
Skin swabbing & 24 & 0 \\
Total & 48 & 5 \\
\hline
\end{tabular}

agar (PBLS; Oxoid) and xylose lysine deoxycholate agar (XLD; Oxoid), and incubated at $37^{\circ} \mathrm{C}$ for $24 \mathrm{~h}$ (selective plating). Typical or suspected Salmonella colonies (PBLS: small, transparent, colorless or pink or opaque white, usually surrounded by a pink or red halo; XLD: pink with or without black centers) were transferred to triple sugar iron (TSI, Oxoid) and lysine iron (LIA; Oxoid) slants, and incubated at $37^{\circ} \mathrm{C}$ for $24 \mathrm{~h}$. When a typical reaction was observed in at least one of the slants (TSI: red slant and yellow butt, with or without $\mathrm{H}_{2} \mathrm{~S}$ formation; LIA: purple butt, with or without $\mathrm{H}_{2} \mathrm{~S}$ formation), cultures were subjected to serological testing with somatic $(\mathrm{O})$ and flagelar $(\mathrm{H})$ polyvalent antisera (Probac do Brasil SA, São Paulo, SP, Brazil), followed by molecular confirmation by using the polymerase chain reaction to detect the presence of invA gene (Galan et al., 1992). Taking into consideration all the confirmation steps just mentioned, final results were expressed as positive or negative for Salmonella spp. in $25 \mathrm{~g}$ or $25 \mathrm{~cm}^{2}$ of each sample and sampling procedure.

\section{Data analysis}

Results from E. coli and Salmonella spp. detection tests for each chicken carcass and each of the four sampling procedures were compared by McNemar test to verify the statistical significance of differences between sampling techniques $(p<0.05)$. Frequencies of positive results were compared by considering the sampling site (near or far from cloacae) and sampling procedure, using the Chi-square test $(p<0.05)$ to verify statistically significant differences. All statistical analyses were conducted by using Statistica 7.0 (StatSoft Inc.,
Tulsa, OK) and XLSTAT 2009.1.02 (Addinsoft USA, New York, NY).

\section{Results}

The frequencies of positive E. coli $\left(\geq 100 \mathrm{cfu} / \mathrm{g}\right.$ or $\left.\mathrm{cm}^{2}\right)$ and Salmonella spp. samples are presented in Table 1. Comparisons of the results obtained from each sampling procedure are presented in Tables 2 and 3. For the detection of E. coli positive carcasses, only nonsignificant differences were observed between samples obtained by rinsing and tissue excision, rinsing and skin excision, and skin excision and tissue excision $(p>0.05)$. However, skin swabbing presented significant differences when compared with the other sampling procedures for E. coli detection $(p<0,05)$. For Salmonella spp., no significant differences were observed among all tested sampling protocols $(p>0.05)$.

The results of frequencies of E. coli and Salmonella spp. isolation considering the tested sampling procedures (except rinsing) as well as while considering the proximity of the cloacae region are shown in Table 4 , and no statistically significant differences were observed $(p>0.05)$.

\section{Discussion}

Considering the obtained results, rinsing and tissue excision sampling procedures resulted in positive $E$. coli detection with a higher frequency than skin swabbing. In addition, only skin swabbing was unable to detect Salmonella spp. from chicken carcasses, whereas all other tested procedures resulted in two positive samples each (Table 1). In a similar study, Gill et al. (2005) were able to identify E. coli in $100 \%$ of chicken carcasses analyzed by using skin excision samples of different sizes $\left(1,10\right.$, and $\left.100 \mathrm{~cm}^{2}\right)$. Gill and Jones (2000) compared tissue excision with swab samples obtained by using three distinct swab materials, and found similar frequencies of positive results for E. coli. In the same work (Gill and Jones, 2000), the influence of the size of the sample area was investigated, and higher frequencies of positive E. coli detection were found to correlate with larger carcass sampling areas. Further, rinsing of chicken carcasses was associated with higher frequencies of positive results for $E$. coli detection than both tissue excision and skin swabbing (Table 1), and is considered the most adequate sampling procedure for the recovery of microorganisms present at low levels, such as E. coli (Gill et al., 2005).

Rinsing and tissue excision protocols yield final results in the same units ( $\geq 100 \mathrm{cfu} / \mathrm{g}$ ), thus enabling direct comparison. Moreover, the observed equivalence between rinsing and

Table 2. Comparison of Distinct Sampling Procedures for the Detection of Escherichia Coli $\left(\geq 100\right.$ CFu/g or CM $\left.{ }^{2}\right)$ in Fresh Chicken Carcasses Collected from Retail Stores located at Viçosa, Minas Gerais, Brazil

\begin{tabular}{|c|c|c|c|c|c|c|}
\hline \multirow[b]{2}{*}{ Paired comparison of sampling procedures } & \multicolumn{2}{|c|}{ Coincident } & \multicolumn{2}{|c|}{ Divergent } & \multirow[b]{2}{*}{$Q^{\mathrm{a}}$} & \multirow[b]{2}{*}{$\mathrm{p}$} \\
\hline & Positive & Negative & Positive: Negative & Negative: Positive & & \\
\hline Skin swabbing: Skin excision & 20 & 22 & 4 & 14 & 5.56 & 0.031 \\
\hline Rinsing: Tissue excision & 32 & 12 & 8 & 8 & 0.00 & 0.804 \\
\hline Skin swabbing: Rinsing & 21 & 17 & 3 & 19 & 11.64 & 0.001 \\
\hline Skin swabbing: Tissue Excision & 21 & 17 & 3 & 19 & 11.64 & 0.001 \\
\hline Skin excision: Rinsing & 29 & 15 & 5 & 11 & 2.25 & 0.210 \\
\hline Skin excision: Tissue Excision & 29 & 15 & 5 & 11 & 2.25 & 0.210 \\
\hline
\end{tabular}

${ }^{\mathrm{a}} \mathrm{McNemar}$ test. $p$-Values lower than 0.05 indicate significant differences between the paired compared sampling methods. 
Table 3. Comparison of Distinct Sampling Procedures for the Detection of Salmonella spp. in Fresh Chicken Carcasses Collected from Retail Stores located at Viçosa, Minas Gerais, Brazil

\begin{tabular}{|c|c|c|c|c|c|c|}
\hline \multirow[b]{2}{*}{ Paired comparison of sampling procedures } & \multicolumn{2}{|c|}{ Coincident } & \multicolumn{2}{|c|}{ Divergent } & \multirow[b]{2}{*}{$Q^{\mathrm{a}}$} & \multirow[b]{2}{*}{$\mathrm{P}$} \\
\hline & Positive & Negative & Positive: Negative & Negative: Positive & & \\
\hline Skin swabbing: Skin excision & 0 & 58 & 0 & 2 & 2.00 & 0.500 \\
\hline Rinsing: Tissue excision & 0 & 56 & 2 & 2 & 0.00 & 0.625 \\
\hline Skin swabbing: Rinsing & 0 & 58 & 0 & 2 & 2.00 & 0.500 \\
\hline Skin swabbing: Tissue Excision & 0 & 58 & 0 & 2 & 2.00 & 0.500 \\
\hline Skin excision: Rinsing & 0 & 56 & 2 & 2 & 0.00 & 0.625 \\
\hline Skin excision: Tissue Excision & 1 & 57 & 1 & 1 & 0.00 & 0.500 \\
\hline
\end{tabular}

${ }^{a}$ McNemar test. $p$-values lower than 0.05 indicate significant differences between the paired compared sampling methods.

tissue excision (Table 2 ) is economically valuable, once rinsing is a nondestructive sampling technique. In agreement with the current study, Cox et al. (2010) compared positive results for $E$. coli from chicken carcasses obtained by rinsing and tissue excision, and also failed to observe significant differences between the sampling protocols. Considering skin swabbing and skin excision, procedures that yield final results in the same units $\left(\geq 100 \mathrm{cfu} / \mathrm{cm}^{2}\right)$, skin excision was able to recover higher frequencies of positive results for $E$. coli (Table 1 ) and presented significant differences when compared with skin swabbing (Table 2), thus being considered a better option despite being destructive.

The absence of differences between the sampling procedures for Salmonella spp. (Table 3) was probably caused by the overall low frequency of positive results identified in the current study. However, in a similar study, Cox et al. (2010) compared the frequencies of Salmonella spp. detection in chicken carcasses sampled by rinsing and tissue excision, and did not find significant differences between the tested procedures. Salmonella spp. is usually present at low levels in chicken carcasses, limiting the use of sampling procedures with low sensitivity, which can underestimate its presence

Table 4. Comparison of Distinct Sampling Procedures Versus Carcass Sampling Sites (Near and Far From the CloAcae Region) FOR the Detection OF ESCHERICHIA COLI $\left(\geq 100 \mathrm{CFU} / \mathrm{G}\right.$ OR $\left.\mathrm{CM}^{2}\right)$ AND SALMONELLA SPP. IN FRESH CHICKEN CARCASSES Collected from Retail Stores Located at Viçosa, Minas Gerais, BraZIL

\begin{tabular}{llccc}
\hline $\begin{array}{l}\text { Sampling } \\
\text { procedure }\end{array}$ & Sampling sites & $\mathrm{n}$ & $\begin{array}{c}\text { Escherichia } \\
\text { coli }\end{array}$ & Salmonella \\
\hline Tissue excision & Near cloacae & 37 & 26 & 1 \\
& $\begin{array}{l}\text { Far away } \\
\text { cloacae }\end{array}$ & 23 & 14 & 1 \\
Skin excision & Near cloacae & 36 & 20 & 2 \\
& Far away & 24 & 14 & 0 \\
Skin swabbing & cloacae & & & \\
& Near cloacae & 36 & 14 & 0 \\
& Far away & 24 & 10 & 0 \\
& $\quad$ cloacae & & & \\
& $\chi^{2}$ & & 9.375 & 4.268 \\
& $p$ & & 0.095 & 0.512 \\
\hline
\end{tabular}

(Cox et al., 2010). Considering this, King et al. (2008) obtained higher frequencies of positive results for Salmonella spp. in chicken carcasses when larger sample volumes were used for microbiological analysis, a procedure that improved the sensitivity of the isolation.

Since E. coli and Salmonella spp. are enteric microorganisms, the sampling site on the carcasses might influence the final results, once regions near the cloacae may be potentially contaminated with Enterobacteriaceae (Palumbo et al., 1999; Cason and Berrang, 2002). However, the absence of significant differences between the results considering the sampling sites and procedures frequencies of E. coli and Salmonella spp. positive results in chicken carcasses submitted to distinct sampling procedures considering the sampling sites (Table 4) may be explained by the characteristics of chicken slaughtering. The avian evisceration step tends to contaminate the carcass in a similar way, and the several subsequent washing steps result in a uniform distribution of microbial contamination throughout the carcass (Mead et al., 1994; Gill et al., 2005). The sampling site of the carcass tends to be more relevant for microbiological analysis of other animal carcasses, such as swine (Palumbo et al., 1999) and cattle (Grau, 1986).

Considering the obtained results, relevant information is presented for food industries and official regulatory organs in choosing the sampling technique that is most convenient and appropriate to obtain the desired microbiological control during production and inspection. These findings are economically valuable, because rinsing preserves the integrity of the carcass for commercial use by the food industry, and provides similar results when compared with tissue and skin excision for detection of both E. coli and Salmonella spp. So, this procedure could be adequately employed in quality control programs and in monitoring the presence of these microorganisms in chicken carcasses.

The current study provided specific information about distinct sampling procedures, allowing both the food industry and official regulatory agencies to apply the most appropriate technique during chicken production, after taking into consideration safety and quality goals. The tested sampling techniques were equivalent for Salmonella spp. detection, as observed for E. coli with the exception of skin swabbing.

\section{Acknowledgments}

L.A. Nero and P.S.A. Pinto are supported by CNPq and FAPEMIG. M.V.C. Cossi and M.V. Almeida are supported by 
CNPq (master scholarship), and M.R. Dias is supported by FAPEMIG (Scientific scholarship).

\section{Disclosure Statement}

No competing financial interests exist.

\section{References}

Álvarez-Astorga M, Capita R, Alonso-Calleja C, Moreno BM, and García-Fernández C. Microbiological quality of retail chicken by-products in Spain. Meat Sci 2002;62:45-50.

Capita R, Prieto M, and Alonso-Calleja C. Sampling methods for microbiological analysis of red meat and poultry carcasses. J Food Prot 2004;67:1303-1308.

Cason JA and Berrang ME. Variation in numbers of bacteria on paired chicken carcass halves. Poult Sci 2002;81:126-133.

Cox NA, Richardson LJ, Cason JA, Buhr RJ, Vizzier-Thaxton V, Smith DP, Fedorka-Cray PJ, Romanenghi CP, Pereira LVB, and Doyle MP. Comparison of neck skin excision and whole carcasses rinse sampling methods for microbiological evaluation of broiler carcasses before and after immersion chilling. J Food Prot 2010;73:976-980.

Galan JE, Ginocchio C, and Costeas P. Molecular and functional characterization of the Salmonella invasion gene invA: homology of InvA to members of a new protein family. J Bacteriol 1992;174:4338-4349.

Ghafir Y, China B, Dierick K, De Zutter L, and Daube G. Hygiene indicator microorganisms for selected pathogens on beef, pork, and poultry meats in Belgium. J Food Prot 2008; 71:35-45

Gill CO, Badoni M, Moza LF, Barbut S, and Griffiths MW. Microbiological sampling of poultry carcass portions by excision, rinsing, or swabbing. J Food Prot 2005;68:2718-2720.

Gill CO and Jones T. Microbiological sampling of carcasses by excision or swabbing. J Food Prot 2000;63:167-173.

Gill CO, Moza LF, Badoni A, and Barbut S. The effects on the microbiological condition of product of carcass dressing, cooling, and portioning processes at a poultry packing plant. Int J Food Microbiol 2006;110:187-193.

Grau FM. Microbiol ecology of meat and poultry. In: Advances in Meat Research, Vol. 2. Pearson AM and Dutson TR (eds.). Westport: AVI Publishing Co., 1986, pp. 1-47.

ISO. Microbiology of Food and Animal Feeding Stuffs-Horizontal Method for the Detection of Salmonella spp. ISO 6579:2002. Geneva: International Organization for Standardization-ISO, 2002.
King S, Galca F, Hornitzky M, and Adams MC. A comparative evaluation of the sensitivity of Salmonella detection on processed chicken carcasses using Australian and US methodologics. Lett Appl Microbiol 2008;46:205-209.

Mead GC, Hudson WR, and Hinton MH. Use of marker organism in poultry processing to identify sites of crosscontamination and evaluate possible control measures. $\mathrm{Br}$ Poult Sci 1994;35:343-354.

Palumbo SA, Klein P, Capra J, Eblen S, and Miller AJ. Comparison of excision and swabbing sampling methods to determine the microbiological quality of swine carcass surfaces. Food Microbiol 1999;16:459-464.

Rasschaert G, Houf K, and de Zutter L. Impact of the slaughter line contamination on the presence of Salmonella on broiler carcasses. J Appl Microbiol 2008;103:333-341.

Reiter MGR, Fiorese ML, Moretto G, López MC, and Jordano R. Prevalence of Salmonella in a poultry slaughterhouse. J Food Prot 2007;70:1723-1725.

Snijders JMA, Janssen MHW, Gerats GE, and Cortiaensen GP. A comparative study of sampling techniches for monitoring carcass contamination. Int J Food Microbiol 1984;1:229-236.

Tsola E, Drosinos EH, and Zoiopoulos P. Impact of poultry slaughter house modernisation and updating of food safety management systems on the microbiological quality and safety of products. Food Control 2008;19:423-431.

USDA. Code of Federal Regulations. Title 9 (Animals and Animals Products), Chapter III (Food Safety and Inspection Service, Department of Agriculture), Part 381 (Poultry Products Inspection Regulations). Washington: Department of Agriculture, 2003.

USDA/FSIS. Microbiology Laboratory Guidebook, 4.04. Washington: USDA/FSIS-United States Department of Agriculture-Food Safety and Inspection Service, 2008.

Vandeplas S, Dauphin RD, Beckers Y, Thonart P, and Théwis A. Salmonella in chicken: current and developing strategies to reduce contamination at farm level. J Food Prot 2010;73:774-785.

Address correspondence to: Luís Augusto Nero, Ph.D.

Departamento de Veterinária Universidade Federal de Viçosa Campus Universitário 36570-000 Viçosa Brazil

E-mail: nero@ufv.br 


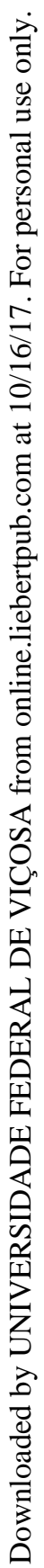

